\title{
Health problems in the temporary housing in Taiwan
}

\author{
Yen-Hsiung Liao \\ Department of Health Sciences, School of Public Health, Kaohsiung Medical University, Kaohsiung, Taiwan; \\ bany0309@yahoo.com.tw
}

Received 22 February 2013; revised 25 March 2013; accepted 3 April 2013

Copyright (C) 2013 Yen-Hsiung Liao. This is an open access article distributed under the Creative Commons Attribution License, which permits unrestricted use, distribution, and reproduction in any medium, provided the original work is properly cited.

\begin{abstract}
To understand the health effects of the temporary housing after the September 1999 earthquake in Taiwan, we conducted the object observation, environmental monitoring, questionnaire survey, and disease analysis in both spring and autumn seasons to rate the presence and magnitude of exposures of environmental hazards. In the hot season more people identified poor ventilation, dampness, hot, odor, and insecurity as sources of hazards. The health effects on the cervix and vagina, liver, and respiratory disease assessed by clinic visits were corresponded to the environmental exposures, and complaints. It was suggested that reducing the risks to temporary housing residences by means of improving housing ventilation and providing community security when the permanent housing was not finished from the experience of Chi-Chi earthquake disaster in Taiwan.
\end{abstract}

Keywords: Earthquake; Temporary Housing; Health Effects; Ventilation; Community Security

\section{INTRODUCTION}

On 21 September 1999, at 01:47, an earthquake of magnitude 7.3 on the Richter scale struck the central area of Taiwan [1]. As a result of the earthquake, more than 100,000 houses were collapsed, 2347 people died, and more than 8000 were injured all over the island. This event was the most profound inland earthquake to occur during the past 100 years in Taiwan.

After Chi-Chi earthquake, the Central Government announced three emergency housing policies, which were temporary houses providing, rental subsides, and $30 \%$-discount public houses sale to support their lives. According to the statistic available in February 2000, 5270 units of temporary housing were constructed: 799 $(15.16 \%)$ units donated from the public sector, 3470
(65.84\%) units donated from private sectors, and 1001 (19.00\%) units donated from Japan [2].

Units were generally one of three sizes: $26.45 \mathrm{~m}^{2}$, $39.47 \mathrm{~m}^{2}, 42.94 \mathrm{~m}^{2}$. Initially only homeowners were eligible to receive temporary houses. Because there were fewer initial applicants than expected, and the heavy demand for temporary housings, eligibility for temporary houses was broadened in November 1999 to include low-income family, physically and mentally disabled family, and aboriginal family. Temporary housing occupation was initially set at one year and later extended to three years after the implementation of "Reconstruction Special Laws" in December 2000.

In Taiwan, the processes of post-quake reconstruction moved in the following subsequences: "Emergency period", "Placement period", and "Reconstruction period". The supply of temporary houses could be in placement period. A number of past studies described about the economic and social impacts of temporary housing policies, such as the needs of employment, income, good lifestyle, and sanitation [3-9]. However, no studies discussed the relationship of housing and health for the temporary housing residences.

To improve preparedness for reconstruction after earthquakes, we must rely on the placement period stably, more understanding about the health, and needs of the temporary housing is an important issue. The studies revealed four aspects including object observation, environmental monitoring, questionnaire, and disease analyses to identify the relationship of the temporary housing and health in order to suggest reconstruction programs accurately.

\section{METHODS}

\subsection{Study Area and Subjects}

We selected Puli township as the study area because the temporary houses were constructed the most that occupied $18.6 \%$ of the total 5270 units in the Nantou County. There were 2486 persons who lived in these 
temporary housing units.

\subsection{Object Observation}

The detail information of the 978 units (12 sites) including location, offering body, size, materials, effective ventilated index (area of opens/area of floor), population volume (persons/house), and number of temporary houses was summarized in the Table 1.

\subsection{Environmental Monitoring}

Making use of potable meters to measure the indoor air environment including thermal \& moisture (Electronic thermal-hygrograph meter; TOMEL CO, Japan), air flow (Mini anemometer, model: ISA-6-3D; SIBATA, Japan), and ammonia level (PAC II ; Drager CO, Germany). Meters were calibrated daily before data collection. The temporary housing sites were clustered into four construction types on the basis of occupancy permit by materials. They included Iron room (including cabinet room, and iron-covered room), DaAi-Tsuchi (including DaAi 1-Tsuchi, and DaAi 2-Tsuchi), Cinyan-Japan (including Cinyan6-Japan, Cinyan7-Japan, and Cinya8Japan), and The salvation army \& Young women's Christian association (TSA\& YWCA) (including Chou-chonlin-TSA, Wuson-TSA, Taumi-TSA, Lanchin-TSA, and Puti-Chanchin-YWCA). The first measurements were conducted in February (cold season) 2000, and the final measurements were conducted in August (hot season) 2000 for the 4 items of indoor air environment, respectively. The environmental data was taken from 09:00 to 16:00 in the both measure periods.

\subsection{Questionnaire}

A structural questionnaire was conducted to interview with the household of the temporary housing residents. The questionnaire included demographic information, environmental health status, and the needs of health and safety. The questionnaire was pre-tested on a sample of 20 cases, and validated by 8 experts. The purpose of questionnaires was to find out the degree of environmental problems, and recommended strategies of health and safety to the government effectively.

\subsection{Disease Analyses}

We reviewed disease data before (during February and August, 1999) and after (during February and August, 2000) the Chi-Chi earthquake in Puli township. The data were mainly abstracted from the clinic visit records of the Burear of National Health Insurance, the only health insurance provider in Taiwan. The international classification disease (ICD-9) was used to define cause of disease.

\subsection{Statistic}

The one-way analysis of variance test and post-hoc statistic were used to compare the significant differences of indoor measurements among the 4 construction types of temporary houses. Cross-tabs with chi-square analysis were used to compare the differences of environmental compliant for the 978 temporary housing in two survey periods. All analyses were performed with SPSS statistical software (SPSS Inc., Chicago, IL) for Window.

\section{RESULTS}

\subsection{Object Observation}

According to statistic available in February 2000, 978 units of temporary houses were constructed in Puli township: 496 units from the domestic private sectors (58 Cabinet room-Evergreen, 14 Iron-covered RoomCGPC, 318 DaAi 1-Tsuchi, and 106 DaAi 2-Tsuchi), 296 units from Japan government (98 Cinyan6-Japan, 150 Cinyan7-Japan, and 48 Cinyan8-Japan), and 186 units from international private sectors (19 Chouchonlin-TSA,

Table 1. Detail information of the 12 temporary housing sites.

\begin{tabular}{|c|c|c|c|c|c|c|}
\hline Name of sites & Size & Wall & Foundation & Area of opens/area of floor & Population volume & No. \\
\hline Cabinet room-Evergreen & $26.45 \mathrm{~m}^{2}$ & metal & $\mathrm{PVC}$ & $8.8 \%$ & 2 & 58 \\
\hline Iron-covered & $42.94 \mathrm{~m}^{2}$ & LPB & $\mathrm{PVC}$ & $18.7 \%$ & 4 & 14 \\
\hline DaAi 1-Tsuchi & $42.94 \mathrm{~m}^{2}$ & LPB & $\mathrm{PVC}$ & $23.0 \%$ & 4 & 318 \\
\hline DaAi 2-Tsuchi & $42.94 \mathrm{~m}^{2}$ & LPB & PVC & $23.0 \%$ & 4 & 106 \\
\hline Cinyan6-Japan & $39.47 \mathrm{~m}^{2}$ & FRP & Tatami & $28.9 \%$ & 3 & 98 \\
\hline Cinyan7-Japan & $39.47 \mathrm{~m}^{2}$ & FRP & Tatami & $28.9 \%$ & 3 & 150 \\
\hline Cinyan8-Japan & $39.47 \mathrm{~m}^{2}$ & FRP & Tatami & $28.9 \%$ & 3 & 48 \\
\hline Chouchonlin-TSA & $42.94 \mathrm{~m}^{2}$ & LPB & PVC & $23.0 \%$ & 4 & 19 \\
\hline Wuson-TSA & $42.94 \mathrm{~m}^{2}$ & LPB & PVC & $23.0 \%$ & 4 & 13 \\
\hline Lanchin-TSA & $42.94 \mathrm{~m}^{2}$ & LPB & $\mathrm{PVC}$ & $23.0 \%$ & 4 & 72 \\
\hline Puti-Chanchin-YWCA & $42.94 \mathrm{~m}^{2}$ & LPB & PVC & $23.0 \%$ & 4 & 50 \\
\hline
\end{tabular}


13 Wuson-TSA, 32 Taumi-TSA, 72 Lanchin-TSA, and 50 Chanchin-YWCA). All the sites were located outside of the city, and all the toilets were built in indoors except the Cainet room-Evergreen. The temporary houses were constructed on the farmland and with light materials, such as light partition board (LPB), fibre reinforced polymer (FRP), and poly vinyl chloride (PVC). The population volume was correlated with the housing sizes. The effective ventilated indies were not out of compass $(\geq 5 \%)$ in all the temporary housing units, however, most of the windows were closed when we surveyed the temporary housing.

\subsection{Environmental Monitoring}

The standard for the indoor air environment was between $15^{\circ} \mathrm{C}$ and $28^{\circ} \mathrm{C}$ for temperatures, between $40 \%$ and $70 \%$ for moistures, more than $0.2 \mathrm{~m} / \mathrm{s}$ for air flow, and less than $0.2 \mathrm{ppm}$ for ammonia, respectively. Table 2 shows the means of the 4 indoor air items among the 4 construction types of temporary houses. There was not any significant difference of indoor air item among the 4 types of temporary houses in cold season and in hot season, respectively (all $p$ values $>0.05$ ). The mean of temperature, and humidity was significantly lower in February than in August in all the 4 types of temporary houses respectively (all $\mathrm{p}$ values $<0.05$ ). The mean of air flow was significantly higher as well as the mean of ammonia level was lower in February than in August in all the 4 types except Iron room of temporary houses, respectively (all p values $<0.05$ ). There were fewer indoor air measurements out of compass in all the 4 construction types of temporary houses in the cold season. However, there were many indoor air measurements out of compass in all the 4 construction types of temporary houses in the hot season. In February: the mean of air flow was lower than the standard tolerance of air flow in iron room. In August: the mean of temperature, and the humidity respectively was higher than the standard tolerance of temperature, and humidity, as well as the air flow was lower than the standard tolerance of air flow in all the 4 construction types of temporary houses; the mean of ammonia level was higher than the standard tolerance of ammonia level in DaAi-Tsuchi, Cinyan-Japan, and in TSA\&YWCA temporary houses, respectively. The mean of ammonia level was not higher than the standard tolerance of ammonia level in Iron room either in February or in August, specifically.

\subsection{Questionnaire}

Table 3 compares the environmental complaints of the temporary housing of the two surveys. There was a great improvement for the drainage capping in the temporary housing, however, the complaint of impeded drainage was still high. Owing to the impeded drainage that could harbor pests, the temporary housing households also complained about the high density of pests in houses in the second survey deservedly.

Table 4 shows the major need of health and safety for the temporary housing households. The major need reported by the first survey was sterilization $(20.2 \%)$, followed by health care (19.2\%), trash management $(18.2 \%)$, community activity (16.9\%), and public order (14\%). By the second survey, the major need reported was sterilization $(22.5 \%)$, followed by health care $(21.3 \%)$, community activities $(20.3 \%)$, and public order $(18.0 \%)$. The greatest percentage of increase in the major need of

Table 2. Indoor air measurements in the 4 construction types of temporary houses.

\begin{tabular}{|c|c|c|c|c|c|}
\hline & Iron room & DaAi-Tsuchi & Cinyan-Japan & TSA \& YWCA & \\
\hline No. & 72 & 424 & 296 & 186 & $\mathrm{P}$ value \\
\hline \multicolumn{6}{|c|}{ Temperature $\left({ }^{\circ} \mathrm{C}\right)$} \\
\hline February & $21.8 \pm 0.5$ & $17.7 \pm 0.2$ & $18.0 \pm 0.3$ & $19.0 \pm 0.4$ & $\mathrm{P}>0.05$ \\
\hline August & $34.3 \pm 0.9^{*}$ & $28.2 \pm 0.5^{*}$ & $28.1 \pm 0.3^{*}$ & $30.2 \pm 0.2^{*}$ & $\mathrm{P}>0.05$ \\
\hline \multicolumn{6}{|c|}{ Moisture (\%) } \\
\hline February & $70.3 \pm 4.7$ & $66.8 \pm 1.8$ & $64.7 \pm 1.1$ & $68.0 \pm 3.6$ & $\mathrm{P}>0.05$ \\
\hline August & $85.2 \pm 5.5^{*}$ & $80.2 . \pm 1.8^{*}$ & $79.0 \pm 1.7^{*}$ & $86.4 \pm 1.0^{*}$ & $\mathrm{P}>0.05$ \\
\hline \multicolumn{6}{|c|}{ Air flow (m/s) } \\
\hline February & $0.13 \pm 0.03^{*}$ & $0.20 \pm 0.05$ & $0.26 \pm 0.07$ & $0.22 \pm 0.06$ & $\mathrm{P}>0.05$ \\
\hline August & $0.11 \pm 0.03^{*}$ & $0.10 \pm 0.01^{*}$ & $0.12 \pm 0.02^{*}$ & $0.10 \pm 0.03^{*}$ & $\mathrm{P}>0.05$ \\
\hline \multicolumn{6}{|c|}{$\mathrm{NH}_{3}(\mathrm{ppm})$} \\
\hline February & $0.16 \pm 0.02$ & $0.17 \pm 0.03$ & $0.20 \pm 0.05$ & $0.19 \pm 0.03$ & $\mathrm{P}>0.05$ \\
\hline August & $0.18 \pm 0.07$ & $0.42 \pm 0.12^{*}$ & $0.33 \pm 0.06^{*}$ & $0.35 \pm 0.05^{*}$ & $\mathrm{P}>0.05$ \\
\hline
\end{tabular}

*: out of compass. 
Table 3. Environmental complaints of the 978 temporary houses in February's and August's surveys, 2000.

\begin{tabular}{|c|c|c|c|}
\hline \multirow[t]{2}{*}{ Item } & February & August & \multirow[b]{2}{*}{$P$ value } \\
\hline & Yes $(\%)$ & Yes $(\%)$ & \\
\hline Drainage capping ${ }^{*}$ & 1.0 & 42.0 & $\mathrm{P}<0.05$ \\
\hline Drainage is impeded ${ }^{*}$ & 30.2 & 44.0 & $\mathrm{P}<0.05$ \\
\hline Stench & 5.8 & 8.2 & $\mathrm{P}>0.05$ \\
\hline The mosquito are many ${ }^{*}$ & 22.4 & 48.9 & $\mathrm{P}<0.05$ \\
\hline The fly are many* & 13.6 & 46.0 & $\mathrm{P}<0.05$ \\
\hline The cockroach are many ${ }^{*}$ & 3.0 & 79.6 & $\mathrm{P}<0.05$ \\
\hline The rats are many ${ }^{*}$ & 1.2 & 87.6 & $\mathrm{P}<0.05$ \\
\hline
\end{tabular}

*: significant difference.

Table 4. Comparison of major need of health and safety for the 978 temporary housings in February's and August's surveys, 2000.

\begin{tabular}{lccc}
\hline Item & February & August & \% increase \\
\hline Sterilization & $20.2 \%$ & $22.5 \%$ & 11.4 \\
Health care & $19.2 \%$ & $21.3 \%$ & 10.9 \\
Trash management & $18.2 \%$ & $10.9 \%$ & -40.1 \\
Community activity & $16.9 \%$ & $20.3 \%$ & 20.1 \\
Public order & $14.0 \%$ & $18.0 \%$ & 28.6 \\
Provides the employment & $9.4 \%$ & $6.0 \%$ & -31.9 \\
Yelp reduction & $2.1 \%$ & $1.0 \%$ & -52.4 \\
\hline
\end{tabular}

health and safety was public order (28.6\%), followed by community activity $(20.1 \%)$ after the disaster reconstruction for 6 months. The increased issues of the major needs implied that environmental safety and social relationship should be emphasized beside the health needs. The major need was sterilization that was well matched to the major complaint; vectors in the surveys.

\subsection{Disease Analyses}

Table 5 showed the major weekly clinic visit rate of the 2486 persons before and after the Chi-Chi earthquake in Puli township. The greatest weekly clinic visit rate before the Chi-Chi earthquake was acute respiratory infections ( $30.08 \pm 8.80$ visits/100 population), follow by infections and inflammatory of skin and subcutaneous (7.84 \pm 2.02 visits/100 population), and dorsopathies ( $4.20 \pm 1.24$ visits/100 population). Correspondingly, the greatest weekly clinic visit rate after the Chi-Chi earthquake was acute respiratory infections $(40.64 \pm 9.70$ visits/100 population), follow by infections and inflammatory of skin and subcutaneous $(9.60 \pm 2.92$ visits/100 population), and dorsopathies $(6.20 \pm 1.78$ visits/100 population). The greatest increased percentage in weekly clinic visit rate resulted from the Chi-Chi earthquake was inflammatory diseases of uterus, cervix, vagina, and vulva (181.25\%), followed by Chronic liver disease and cirrhosis $(127.78 \%)$. The health effects were corresponded to the environmental exposures, complaints, and needs in the temporary housing.

\section{DISCUSSION}

Housing is an important determinant of health, and substandard housing is a major public health issue [10]. The results of this study indicated that people living in the temporary houses were exposed to indoor and outdoor hazards. The assessment methods used-researcher observations via object measurements, environmental monitoring, and questionnaire survey_identified substantial exposures to poor ventilation, hot, damp, vectors, and insecurity were noted. The health effects assessed by clinic visits corresponded to the environmental exposures, complaints, and health needs for the temporary housing.

Ventilation is in many cases used to control the thermal environment or humidity in buildings [11]. The inadequate ventilation could increase interior temperature and moisture, which contribute to an increase in emission of volatile chemical [12]. Therefore, the indoor toilet built combined with the poor ventilation might explain the high concentration of ammonia in hot season in the study. The damp house provides a nurturing environment for mites, coaches, molds, fungi, respiratory bacteria, and virus all of which play a role in respiratory, skin, and vaginal disease pathogenesis of the housing residences [13-18]. The impeded drainage in out doors can harbor 
Table 5. The major weekly clinic visit rate of the 2486 persons before and after the Chi-Chi earthquake in Puli township.

\begin{tabular}{lccc}
\hline Disease (ICD-9) & $\begin{array}{c}\text { Pre-earthquake stage } \\
\text { clinic visits/100 }\end{array}$ & $\begin{array}{c}\text { Post-earthquake stage } \\
\text { clinic visits/100 }\end{array}$ & $\begin{array}{c}\text { \% increase in } \\
\text { clinic visit rate }\end{array}$ \\
\hline Inflammatory diseases of uterus, cervix, vagina, and vulva (615 - 616) & $1.92 \pm 0.52$ & $5.40 \pm 1.32$ & 181.25 \\
Chronic liver disease and cirrhosis (571) & $0.72 \pm 0.21$ & $1.64 \pm 0.43$ & 127.78 \\
Gastroenteritis and colitis (535, 558, 564, 577) & $3.52 \pm 1.02$ & $5.68 \pm 1.30$ & 61.36 \\
Ischaemic heart disease (410 - 414) & $0.96 \pm 0.28$ & $1.48 \pm 0.40$ & 54.17 \\
Dorsopathies (720 - 724) & $4.20 \pm 1.24$ & $6.20 \pm 1.78$ & 47.62 \\
Acute respiratory infections (460 - 466) & $30.08 \pm 8.80$ & $40.64 \pm 9.70$ & 35.11 \\
Osteoarthrosis and unspecific disorders (715, 716, 719) & $1.84 \pm 0.58$ & $2.32 \pm 0.71$ & 6.09 \\
Infections and inflammatory of skin and subcutaneous tissue (680 - 698) & $7.84 \pm 2.02$ & $9.60 \pm 2.92$ & 22.45 \\
Influenza (487) & $1.68 \pm 0.50$ & $1.84 \pm 0.55$ & 9.52 \\
Osteoporosis (733) & $1.44 \pm 0.44$ & $1.56 \pm 0.46$ & 8.33 \\
\hline
\end{tabular}

Pre-earthquake stage: during February and August, 1999. Post-earthquake stage: during February and August, 2000.

pests, which can then infest homes.

Excessive indoor temperature has been linked with irritability and social intolerance [19]. Damp and moldy indoor conditions may be associated with anxiety and depression [20]. The promotion of worm and moist environment of the perineal area could increase the vitality of the etiological agents (Gardnerella vaginalis, Candida albicans, and Trichomonas vaginalis) of cervicovaginitis in women [21,22].

The psychosocial burdens of homelessness were associated with weakening the immune system as responsible factor for the incidence of vulvovaginal mycosis also [23-25]. The second need of health and safety for the 978 temporary housing residents reported in the first and second surveys was health care respectively implied hat the victims were experienced the homeless stress also.

Social dimensions of community also affect health. Sampson et al. suggested that rates of neighborhood violence were lower in areas with high collective efficacy (a combination of trust, social cohesion, and informal social control) [26]. In addition, physical insecurity and violence can cause people to stay in their homes, thus limiting physical activity [27]. The temporary housing residents may have greater prevalence of irregular dietary habits, more alcohol intake, smoking habit, sleep disturbance, nervous complaints lower HDL-cholesterol level, and high triglyceride level, compared the control group. These data indicate that earthquake-induced stress may influence liver function and lipid metabolism; leading to increase risks of various health impairments for the earthquake victims [28]. There was a higher percentage increase in weekly clinic visit rate for chronic liver disease and cirrhosis of the temporary housing residences in the studies. Our results agreed with Mayumi's suggestion.

Although temporary housing is not a key factor in ending homelessness, temporary housing occupation still set to three years because the permanent housing was not finished. However, we can reduce the risks to temporary housing residences by means of improving house ventilation and providing community security from the experience of Chi-Chi earthquake disaster.

\section{ACKNOWLEDGEMENTS}

This work was supported by fund DOH-TD-1218 from the Department of Health, Taiwan.

\section{REFERENCES}

[1] Huang, B.S., Chen, K.C., Huang, W.G., Wang, J.H., Chang, D.M., Huang, R.D., Chiu, H.C. and Tsai, C.C. (2000) Characteristics of string ground motion across a thrust fault tip from the September 21, 1999, Chi-Chi, Chinese Taipei earthquake. Geophysical Research Letters, 27, 2729-2732. doi:10.1029/2000GL011396

[2] 921 Earthquake Post-Disaster Recovery Commission (2000) Q \& A for post-quake reconstruction (in Chinese). Executive Yuan of Republic of China Publisher, Taiwan.

[3] Jonson, C. (2007). Strategic planning for post-disaster temporary housing. Disasters, 31, 435-458. doi:10.1111/j.1467-7717.2007.01018.x

[4] Bolin, R. and Stanford, L. (1998) The Northridge earthquake: Community-based approaches to unmet recovery needs. Disasters, 22, 21-38. doi:10.1111/1467-7717.00073

[5] Daley, W.R., Karpati, A. and Sheik, M. (2001) Needs assessment of the displaced population following the August 1999 earthquake in Turkey. Disasters, 25, 67-75.

[6] Wu, J.Y. and Lindell, W.K. (2004) Housing reconstruction after two major earthquake: The 1994 Northridge earthquake in the United States and the 1999 Chi-Chi earthquake in Taiwan. Disasters, 28, 63-81. doi:10.1111/j.0361-3666.2004.00243.x

[7] Pinera, J.F., Reed, R.A. and Njiru, C. (2005) Restoring sanitation services after an earthquake: Field experience 
in Bam, Iran. Disasters, 29, 222-236. doi:10.1111/j.0361-3666.2005.00288.x

[8] Badri, S.A., Asgary, A., Eftekhari, A.R. and Levy, J. (2006) Post-disaster resettlement, development and change: A case study of the 1990 Manjil earthquake in Iran. Disasters, 30, 451-468.

doi:10.1111/j.0361-3666.2006.00332.x

[9] Jonson, C. (2007) Impacts of prefabricated temporary housing after disasters: 1999 earthquakes in Turkey. Habital International, 31, 36-52. doi:10.1016/j.habitatint.2006.03.002

[10] Krieger, J. and Higgins, D.L. (2002) Housing and health: Time again for public health action. American Journal of Public Health, 92, 758-768. doi:10.2105/AJPH.92.5.758

[11] Seppanen, O.A. and Fisk, W.J. (2004) Summary of human responses to ventilation. Indoor Air, 14, 102-118. doi:10.1111/j.1600-0668.2004.00279.x

[12] Parthasarathy, S., Maddalens, R.L., Russell, M.R. and Apte, M.G. (2011) Effect of temperature and humidity on formaldehyde emissions in temporary housing units. Journal of the Air \& Waste Management Association, 61, 689695. doi:10.3155/1047-3289.61.6.689

[13] Verhoeff, A.P., van Strien, R.T., van Wijnen, J.H. and Brunekreef, B. (1995) Damp housing and childhood respiratory symptoms: The role of sensitization to dust mites and molds. American Journal of Epidemiology, 141, 103110 .

[14] Karim, Y.G., Ijaz, M.K., Sattar, S.A. and Johnson-Lussenburg, C.M. (1985) Effect of relative humidity on the airborne survival rhinovirus-14. Canadian Journal of Microbiology, 31, 1058-1061. doi:10.1139/m85-199

[15] Oie, L., Nafstad, P., Botten, G., Magnus, P. and Jaakkola, J.K. (1999) Ventilation in homes and bronchial obstruction in young children. Epidemiology, 10, 294-299. doi:10.1097/00001648-199905000-00018

[16] Spinillo, A., Bernuzzi, A.M., Cevini, C., Gulminetti, R., Luzi, S. and De Santoio, A. (1997) The relationship of bacterial vaginosis, candida and trichomonas infection to symptomatic vaginitis in postmenopausal women attending a vaginitis clinic. Maturitas, 27, 253-260. doi:10.1016/S0378-5122(97)00038-8

[17] Wargocki, P., Sundell, J., Bischof, W., Burndrett, G., Fanger, P.O., Gyntelberg, F., Hanssen, S.O., Harrison, P., Pickering, A., Seppanen, O. and Wouters, P. (2002) Ventilation and health in non-industrial indoor environment: Report from a European multidisciplinary scientific consensus meeting (EUROVEN). Indoor Air, 12, 113-128. doi:10.1034/j.1600-0668.2002.01145.x

[18] Phillips, C.J., Pines, M.K., Latter, M., Muller, T., Peth- erick, J.C., Norman, S.T. and Gaughan, J.B. (2010) The physiological and behavioral responses of steers to gaseous ammonia in simulated long-distance transport by ship. Journal of Animal Science, 88, 3579-3589. doi:10.2527/jas.2010-3089

[19] Center for Disease Control and Prevention (2001) Heatrelated deaths-Los Angeles county, California, 19992000, and United States, 1979-1998. MMWR, 50, 623626.

[20] Hyndman, S.J. (1990) Housing dampness and health amongst British Bengalis in east London. Social Science \& Medicine, 30, 131-141. doi:10.1016/0277-9536(90)90336-Q

[21] Ozturk, C.E., Ozdemir, J., Yavuz, T., Kaya, D. and Behcet, M. (2006) Etiologic agents of cervicovaginitis in Turkish women. Saudi Medical Journal, 27, 1503-1507.

[22] Donders, G.G., Mertens, I., Bellen, G. and Peickmans, S. (2011) Self-elimination of risk factors for recurrent vaginal candidosis. Mycoses, 54, 39-45.

doi:10.1111/j.1439-0507.2009.01754.x

[23] Burg, M.A. (1994) Health problems of sheltered homeless women and their dependent children. Health \& Social Work, 19, 125-131.

[24] Lutgendorf, S.K., Reimer, T.T., Harvey, J.H., Marks, G., Hong, S.Y., Hillis, S.L. and Lubaroff, D.M. (2001) Effects of housing relocation on immunocompetence and psychosocial functioning in older adults. Journals of Gerontology Series A: Biological Sciences and Medical Sciences, 56, 97-105. doi:10.1093/gerona/56.2.M97

[25] Saito, K., Aoki, H., Fujiwara, N., Goto, M., Tomiyama, C. and Iwasa, Y. (2013) Association of urinary 8-OHdG with lifestyle and body composition in elderly natural disaster victims living in emergency temporary housing. Environmental Health and Preventive Medicine, 18, 72-77. doi:10.1007/s12199-012-0284-8

[26] Sampson, R.J., Raudenbush, S.W. and Earis, F. (1997) Neighborhoods and violent crime: A multilevel study of collective efficacy. Science, 277, 918-924. doi:10.1126/science.277.5328.918

[27] Fullilove, M.T., Heon, V., Jimenez, W., Parsons, C., Green, L.L. and Fullilove, R.E. (1998) Injury and anomie: Effects of violence on an inner-city community. American Journal of Public Health, 88, 924-927. doi:10.2105/AJPH.88.6.924

[28] Kako, M. and Ikeda, S. (2009) Volunteer experiences in community housing during the great Hanshin-Awaji earthquake, Japan. Nursing and Health Sciences, 11, 357-359. doi:10.1111/j.1442-2018.2009.00484.x

FRP: Fibre reinforced polymer;

TSA: The salvation army;

YWCA: Young women's Christian association.

CGPC: China general plas
PVC: Poly vinyl chloride;

LPB: Light partition board; 